\title{
Computerized Transaxial Tomography: Its Role in the Post-Operative Tumor Case
}

\author{
G. WORTZMAN
}

\begin{abstract}
SUMMARY: The role of computerized transaxial tomography (CTT) of the brain in 100 post-operative tumor cases is assessed. CTT proves an accurate method of determining tumor recurrence and in evaluating such complications as intracerebral hemorrhage, subdural or extradural hemorrhage, cerebral infarction, hydrocephalus and shunt patency. Its accuracy decreases the need for interventional procedures. Its usefulness may be limited by the presence of metal clips or plates, by radio-opaque contrast media or intracranial air.
\end{abstract}

RÉSUMÉ: Le rôle de la tomographie transaxiale programmée (CTT) du cerveau dans 100 cas de tumeurs postopératoires est évalué. Le CTT semble être une méthode exacte pour déterminer la présence des récidives tumorales et pour évaluer les complications, telles l'hémorragie intracérébrale, l'hémorragie subdurale et extradurale, l'infarctus cérébral, l'hydrocéphalie et la libre circulation d'un shunt. Son efficacité est telle qu'elle diminue la nécessité de procédures agressives. Son utilité peut être limitée par la présence de pinces ou de plaques de métal, par des média de contraste radio-opaques, ou par l'air intracrânien.

Presented in part at the 44th Annual Meeting of the Royal College of Physicians and Surgeons of Canada. Winnipeg, Manitoba, January 22-25, 1975.

From the Division of Neuroradiology, Toronto General Hospital, Toronto, Ontario.

Reprint requests to $\mathrm{Dr}$. George Wortzman, Department of Radiology, Toronto General Hospital, Toronto, Canada MSG $1 \mathrm{L7}$.
The advent of computerized transaxial tomography (CTT) of the brain is changing the sequence and pattern of neurological and neurosurgical investigation and practice. Its role as the prime investigative modality in a wide variety of neurological problems is now apparent. An extensive literature regarding CTT using the EMI scanner has appeared in the past two years. These manuscripts have dealt with the principles of operation and the general applications of this new technique (Ambrose, 1973, 1974; Baker et al., 1974; Davis and Pressman, 1974; New et al., 1974; Paxton and Ambrose, 1974).

Other papers have dealt with technical considerations (Hounsfield, 1973; Ledley et al., 1974; McCullough et al., 1974; Perry and Bridges, 1973; Peters et al., 1973) plus its use in specific problems such as intracerebral tumors (Gawler et al ., 1974), the orbit (Ambrose et al., 1974; Lampert et al., 1974), intracerebral hemorrhage (Scott et al., 1974) and, with the use of the ACTA body scanner, syringomyelia (Dichiro et al., 1975).

Assessment of the post-operative tumor case is difficult and a review of CTT scans in 100 cases was undertaken to determine its special advantages and its limitations in this area of neurological practice (Table I).

In this particular application, CTT furnishes information and permits conclusions largely unattainable by other methods, and is free from some of their inherent problems secondary to the previous surgery. CTT obviates almost completely the need for ventriculography or pneumoencephalography. CTT may be described as a method of soft tis- sue radiography with visualization of any CSF containing space, with easy portrayal of mass lesions plus angiographic features when supplemented by contrast enhancement. CTT also replaces a large percentage of angiograms and isotope scans. Both these techniques have relatively limited value in the postoperative tumor case due to changes secondary to the surgical resection and/or the bone flap itself.

The information obtained by CTT is best summarized as changes (a) in the early post-operative, and (b) in the late post-operative, case. The cases have not been divided into supra and infra tentorial sites for the problems and applications are identical.

\section{(A) The Early Post-Operative Case}

Here the problems are not of tumor recurrence but of determination of post-operative intracerebral hemorrhage, of subdural or extradural hematoma, of infarction. of shunt patency and of hydrocephalus.

A post-operative hematoma is recognized as an area of "increased density" i.e.: a white area on the polaroid taken from the cathode ray tube image. This is due to the greater attenuation of the $x$-ray beam pas-

Table I

Post-Operative Tumors 100 Cases

No

\begin{tabular}{|c|c|c|}
\hline & Recurrence & Recurrence \\
\hline $\left.\begin{array}{l}\text { Gliomas, } \\
\text { Astrocytomas, } \\
\text { Acoustics }\end{array}\right\}$ & 38 & 22 \\
\hline Meningiomas & 7 & 17 \\
\hline Hemangioblastomas & 4 & 2 \\
\hline Orbital Tumors & 2 & 2 \\
\hline Melanomas* & & 6 \\
\hline
\end{tabular}

* All primaries extracranial 
sing through this area of increased density; increased because the congealed blood has a density greater than adjacent brain tissue. An illustrative case (Fig. 1) is a right cerebellar hemangioblastoma where only partial removal was possible. The hematoma is well shown with the remaining tumor mass only evident antero-medially to the hematoma after contrast enhancement.

Subdural hematomas may be secondary to the surgery itself or to the shunt. The appearance of the hematoma is dependent on its age with resulting differences in attenuation, graduating from the acute blood clot (with EMI figures ranging up to 40-45) down to the later subdural hematoma with density attenuation figures in the same range as cerebro-spinal fluid $(0-10)$. The lesions may be bilateral as shown in an elderly patient scanned three weeks after a resection of a left cerebellar tumor mass (Fig. 2). The nature of a similar area of decreased density in the left cerebello-pontine angle was not verified surgically.

The evaluation of ventricular size and shunt patency is also simple to demonstrate with CT scanning (Fig. 3 ) as is hydrocephalus (Fig. 4).

(B) The Late Post-Operative Case

Here the problems are primarily tumor recurrence and also the visualization of porencephalic cysts and, as in the early post-operative case, the diagnosis of hydrocephalus, of shunt patency and of cerebral infarction.

In Table $\mathrm{I}$, the case material is subdivided as to recurrence of the tumor, except for the melanoma cases which will be discussed separately.

Recurrence is evaluated in the light of (1) the mass effect, and (2) tumor vascularity emphasized by contrast enhancement. The infusion of an adequately large bolus of iodinated contrast media allows one to light up the vascular component of a tumor. Our practise is to inject 90 cc's of Hypaque M-60 intravenously as rapidly as possible immediately prior to a repeat scan following the routine scan. The problem in diagnosis is the case in which an area of decreased density without mass ef-
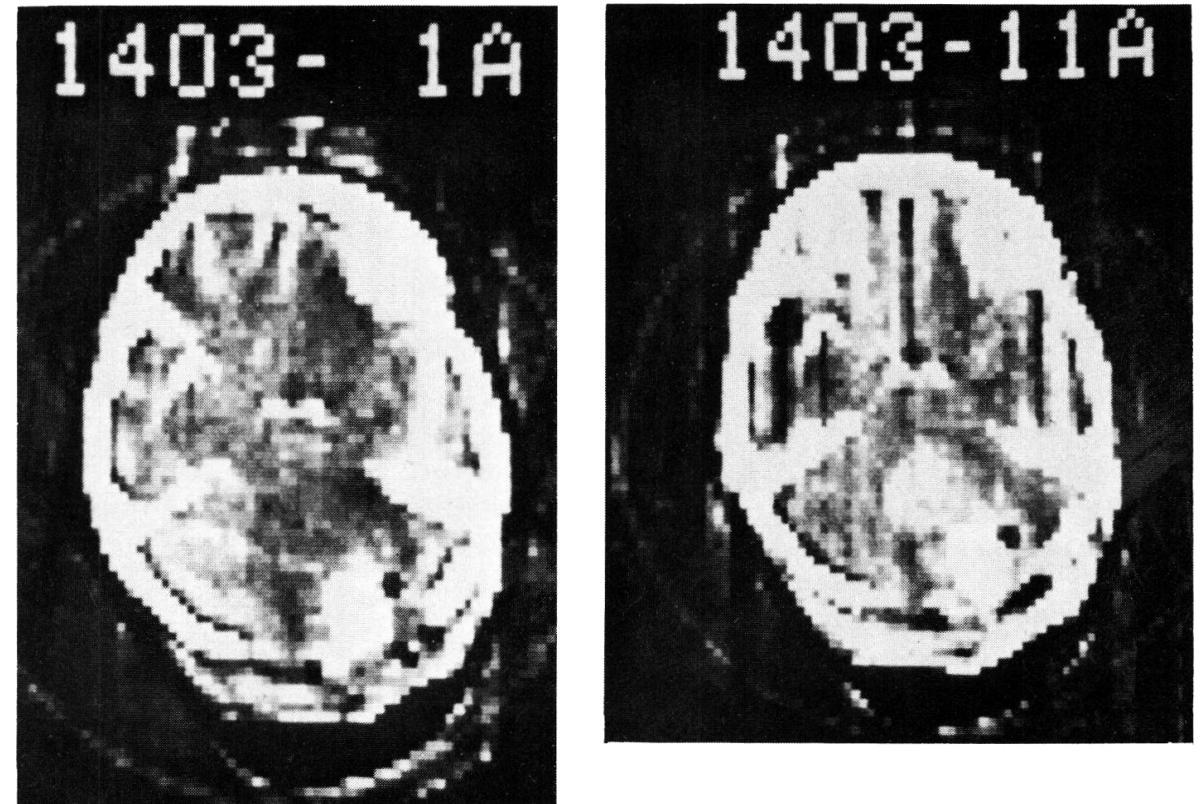

Figure 1-An area of increased density is seen immediately adjacent to the right occipital bone defect following the partial resection of a deep hemangioblastoma (1A). Following contrast enhancement, an area of increased density appears lying antero-medial to the earlier and unchanged area of increased density indicating the site of the unresectable tumor mass (11A). The unchanged area of density is a post-operative hematoma. A small area of decreased density lateral to the hematoma indicates air still present in this study done the day following surgery. fect is seen. Here, the opinion must be guarded stating that the decreased density may be due to a relatively avascular tumor or postoperative fibrosis and/or necrosis secondary to the surgery or radia- tion. A recurrence is not ruled out if there is no mass effect or tumor vascularity, for the tumor may be of low grade, avascular, and of infiltrative nature with the surgical resection of such a degree as to prevent the ap-
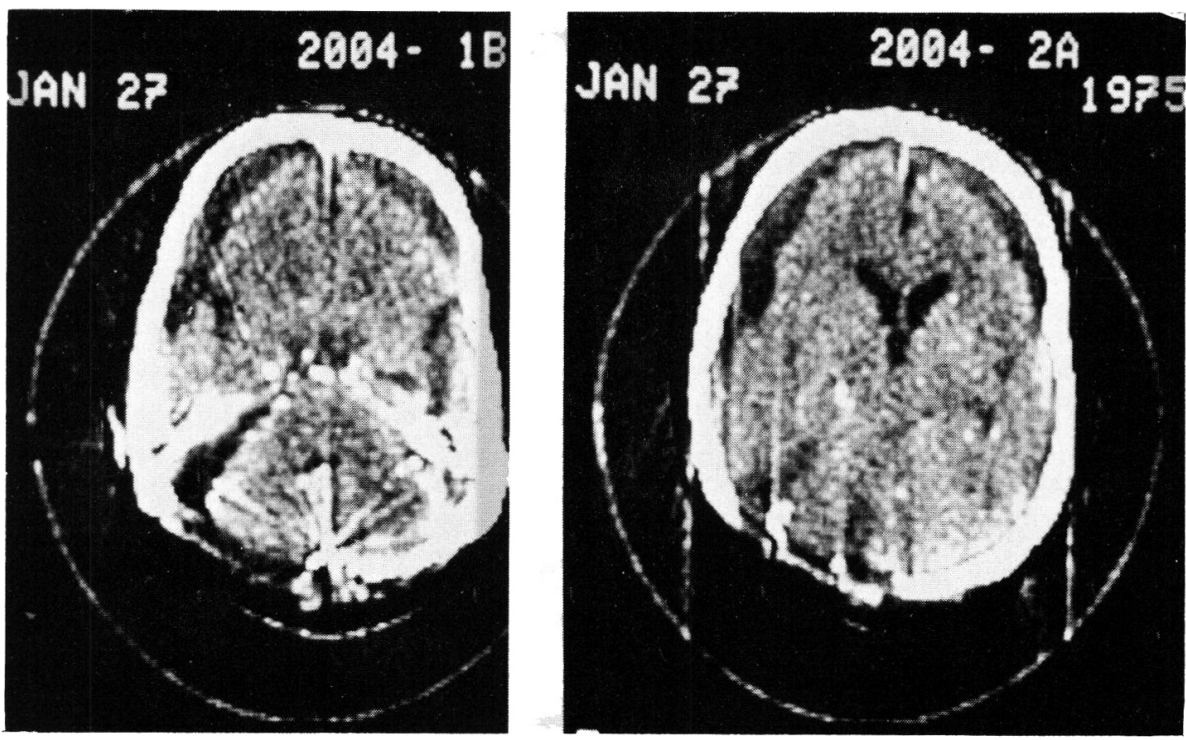

Figure 2-An area of decreased tissue density lies between cerebral cortex and bone (levels $1 \mathrm{~B}$ and $2 \mathrm{~A}$ ) representing bilateral subdural hematomas three weeks after a left cerebellar tumor resection. Radial streaking (level 1B) is from metal clips in the posterior fossa. 
pearance of a mass effect. Thus the term non-recurrence means only that a mass effect or tumor vascularity are not present.

Problems in diagnosis may be compounded by factors such as patient movement; artefacts due to metallic clips, gauze or plates; or artefacts due to air or opaque contrast medium from previous radiological investigation. These are in addition to artefacts that may be due to defects in the scanner such as a loose collimator, a loose head box, poor indexing in rotation, or insufficient attention to meticulous radiographic techniques.

\section{Illustrative Cases are} as Follows:

Distortion, displacement or obliteration of a ventricle, the displacement of the pineal or a choroid plexus indicates a mass effect and recurrence of tumor. With these findings on scanning, contrast en-
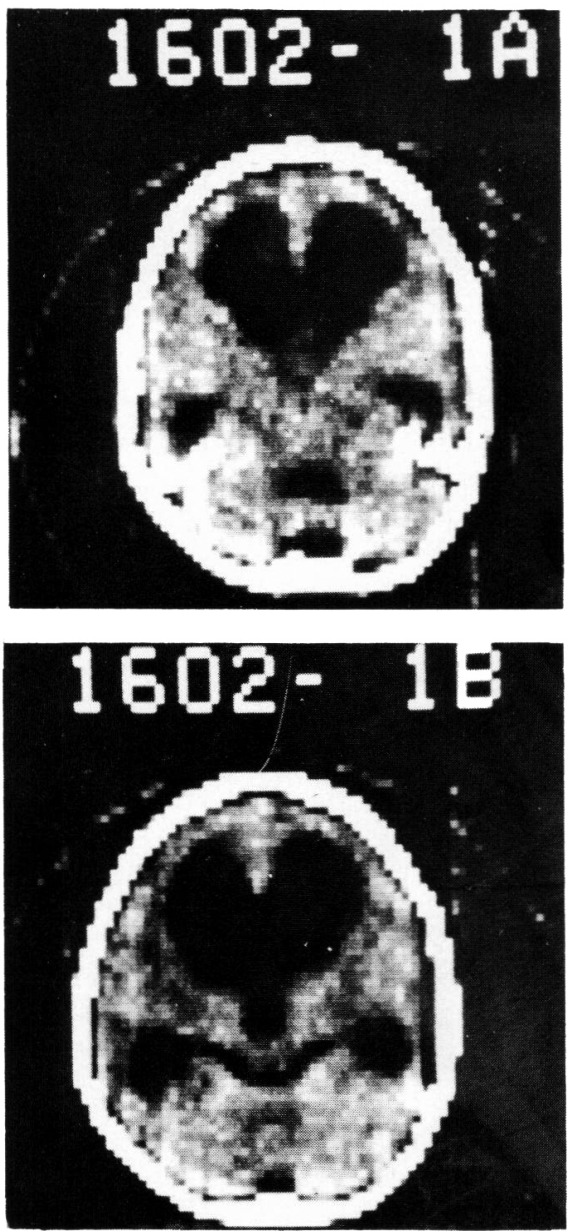
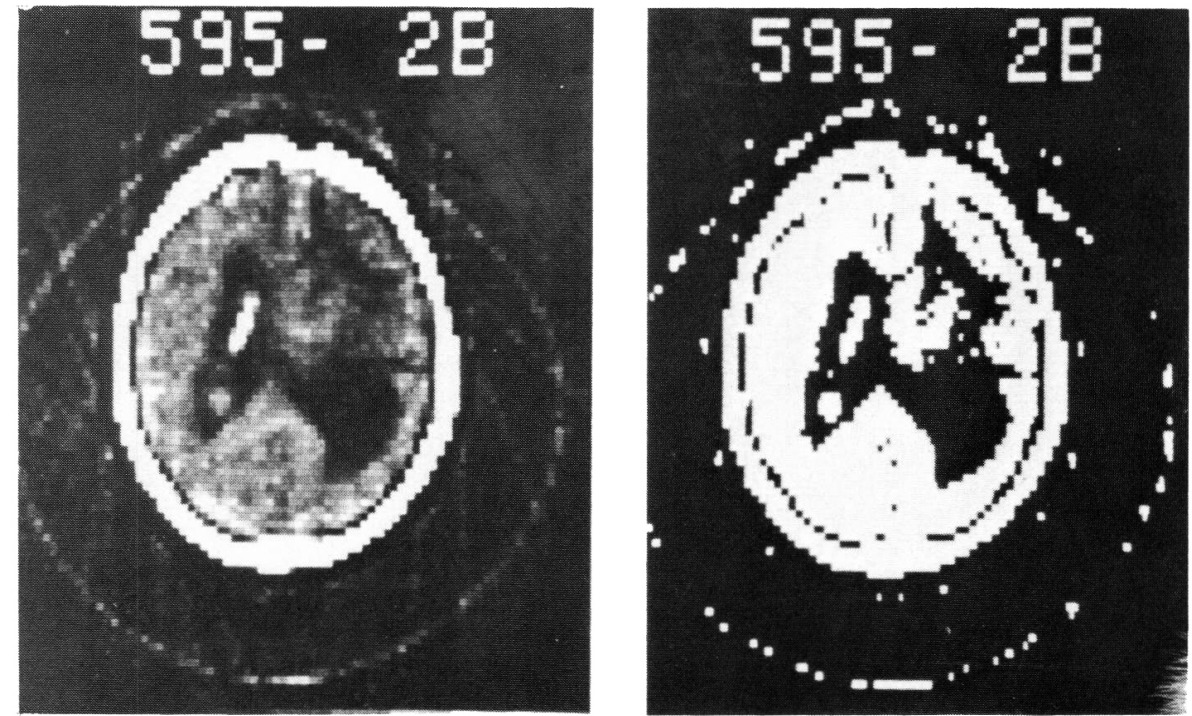

Figure 3-Post-operative thalamic glioma. A shunt is present in the left lateral ventricle with tumor mass now projecting up into the right lateral ventricle causing its obstruction. Right ventricular shunting relieved the unilateral hydrocephalus and the increased intracranial pressure. No other diagnostic procedure was necessary.

hancement is usually not necessary either for a supratentorial (Fig. 5) or an infratentorial lesion (Fig. 6). The area of tumor infiltration may be of decreased, normal or increased density with the degree of X-Ray attenuation dependent on tumor vascularity or calcification. Tumor infiltration may be masked when adjacent to bone, as in a low basal or high vertex level of cut.

When a mass effect is not present, contrast enhancement must be done and may give valuable information as to the site of a vascular nodule in a cystic lesion or the bilateral spread of a tumor (Fig. 7).

Twenty-four cases of postoperative meningiomas were studied with 17 showing non-recurrence reflecting the benign nature of the tumor. There may be difficulties in tumor localization by radionucleide scanning in post-operative tumors due to the bone flap itself even years later (Fig. 8). As in gliomas, mening-

Figure 4-Post-operative posterior fossa ependymoma with marked hydrocephalus. There is symmetrical dilatation of lateral ventricles (all levels), of temporal horns (levels 1A and B), also dilatation of the third (level IB) and fourth ventricles (level 1A).
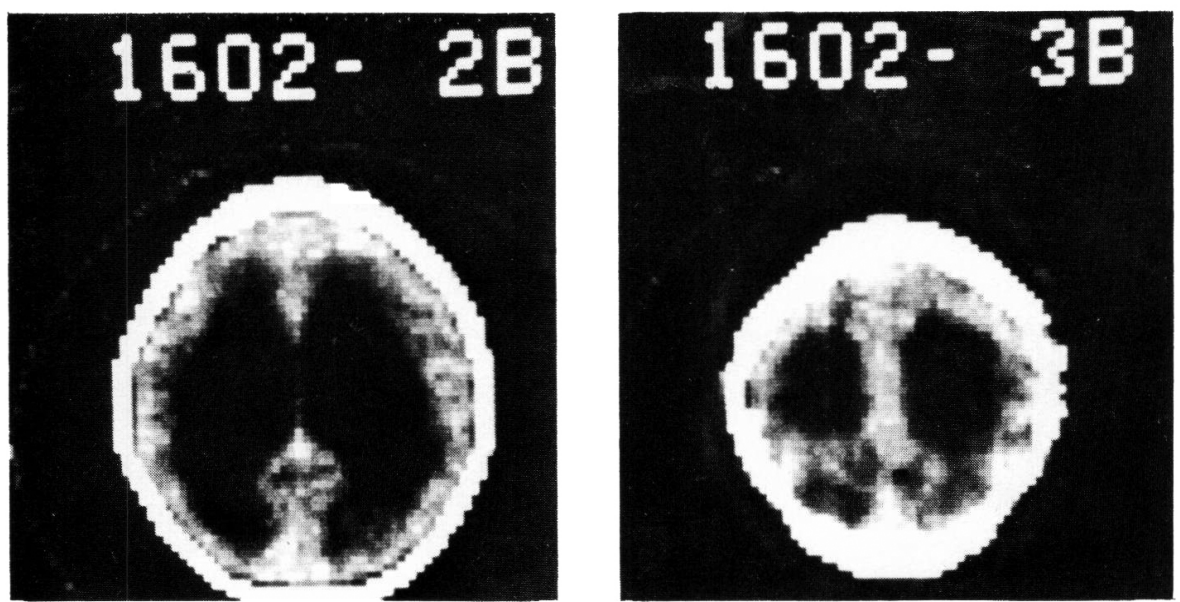

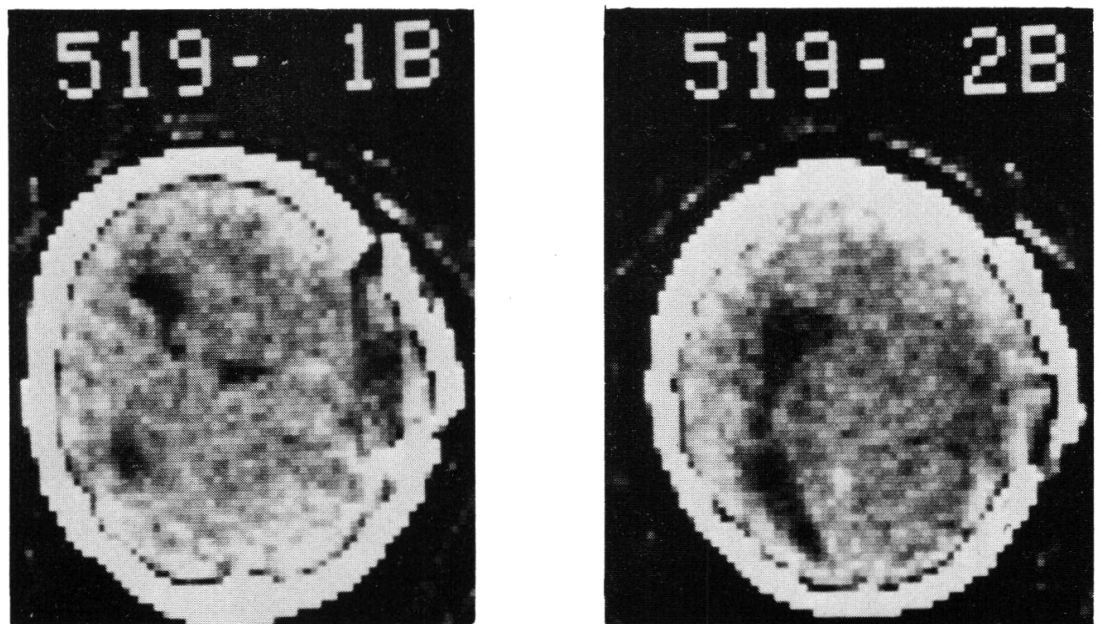

Figure 5-Post-operative right glioblastoma. The left ventricle body is displaced to the left by spread of the tumor across the midline causing a local deformity of the body (level 2B). Increased intracranial pressure has displaced the bone flap laterally (levels 1B, 2A and 2B). Metal clips beneath the bone flap (level 2A) creates radial streaking. Contrast enhancement was not necessary in view of the mass effect and tumor recurrence shown.
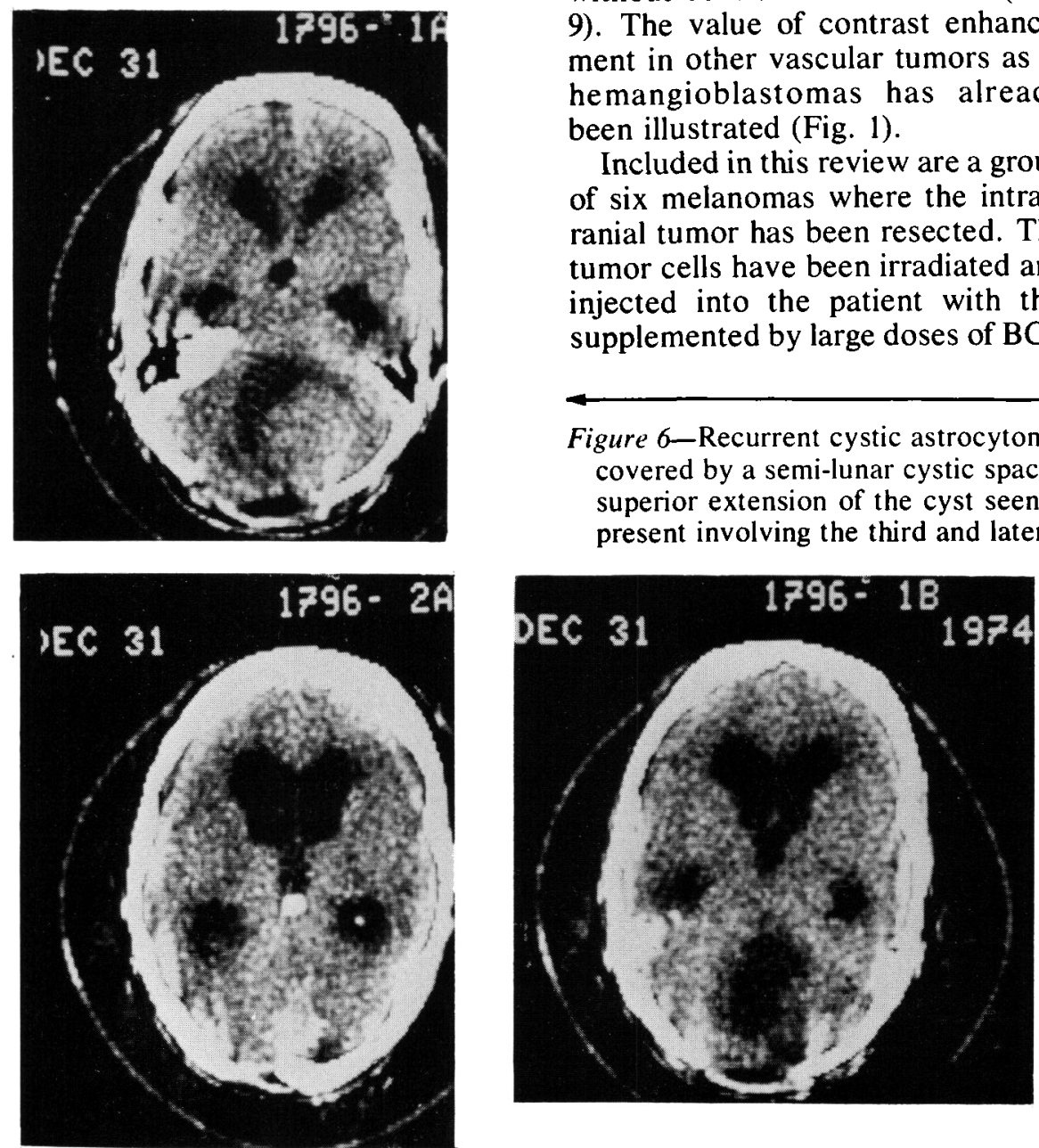

iomas may be difficult to visualize without contrast enhancement (Fig. 9). The value of contrast enhancement in other vascular tumors as in hemangioblastomas has already been illustrated (Fig. 1).

Included in this review are a group of six melanomas where the intracranial tumor has been resected. The tumor cells have been irradiated and injected into the patient with this supplemented by large doses of $B C G$
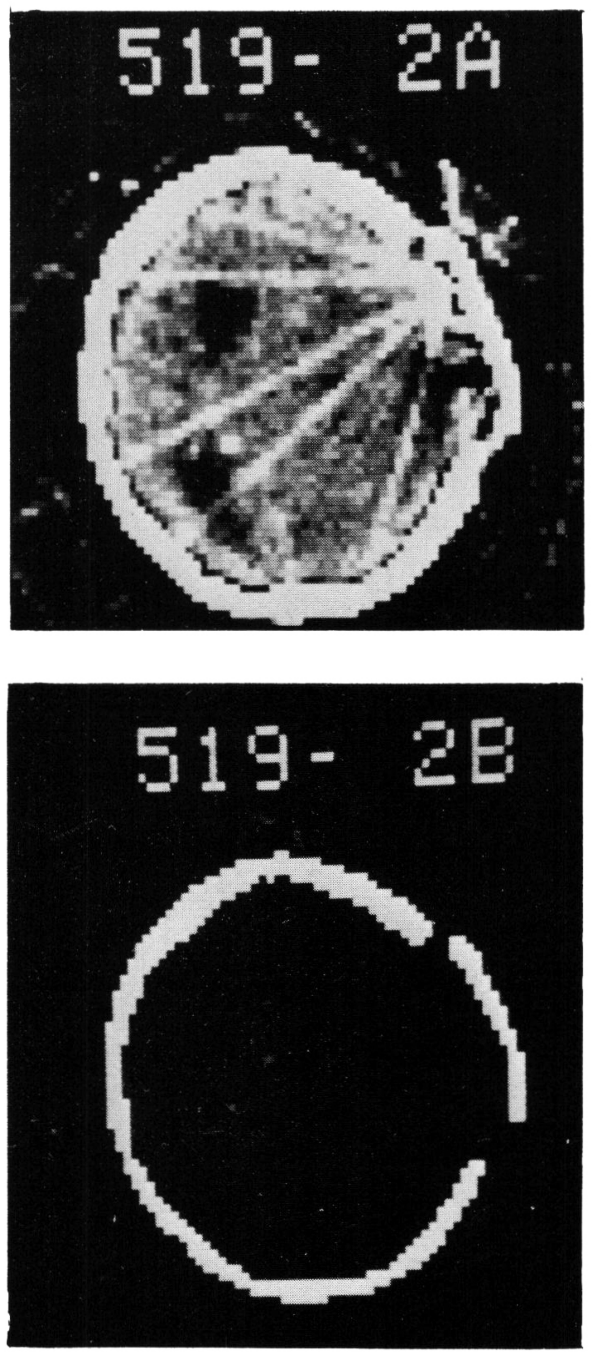

Figure 6-Recurrent cystic astrocytoma of the right cerebellum. The tumor nodule is covered by a semi-lunar cystic space (level IA) of decreased density with a further superior extension of the cyst seen on level $1 \mathrm{~B}$. An obstructive hydrocephalus is present involving the third and lateral ventricles (levels $2 \mathrm{~A} \& 2 \mathrm{~B}$ ).

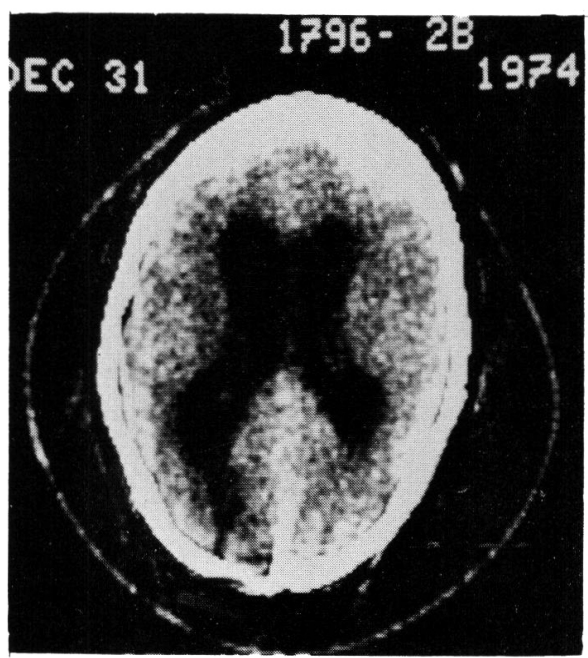



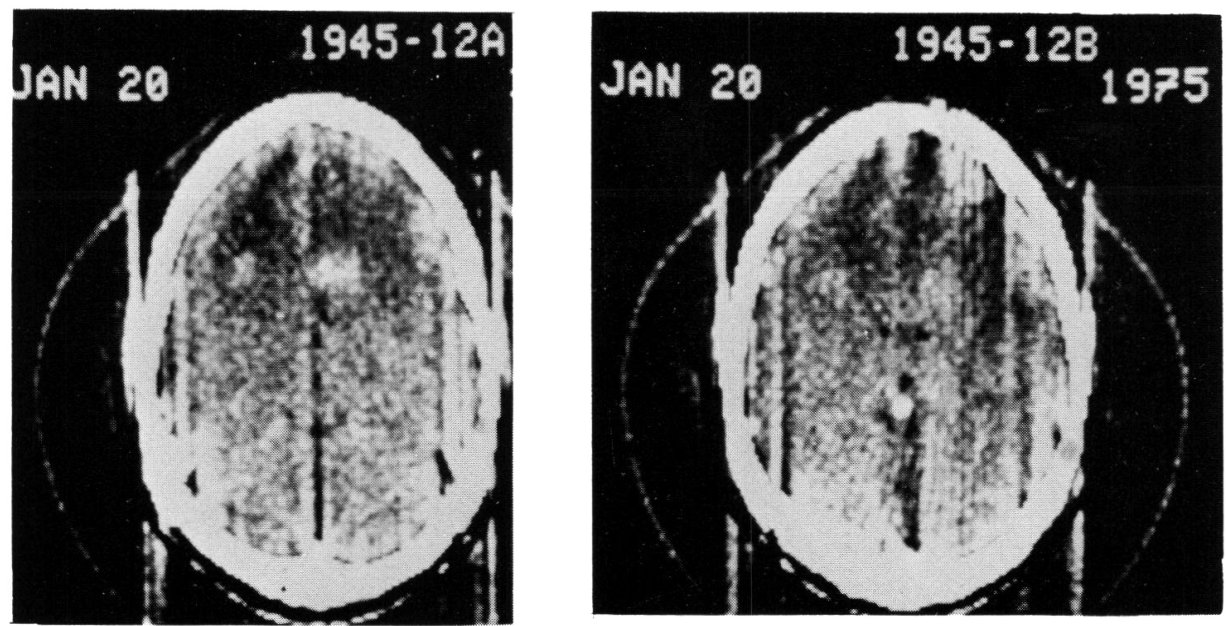

Figure 7-Post-operative grade II right frontal glioblastoma following contrast enhancement. No midline shift is noted but both anterior horns are displaced posteriorly (level 12B). Ill defined areas of decreased density are present bilaterally in the frontal lobes on the pre-contrast study. Radial streaking is present (level 12B) from metal clips in the right frontal lobe with further artefacts in the form of vertical streaking due to patient movement. Following contrast enhancement, areas of tumor vascularity are seen bilaterally in all levels surrounded by areas of low density indicating edema or tumor of lower vascularity.

as a form of immunotherapy. CTT scanning has proven the simplest and most efficacious method of follow up as to recurrence (Fig. 10). The patient illustrated had three resections of a melanoma mass, two resections governed only by the CTT results.

CTT scanning is also of value in the follow up of orbital tumors. The four cases listed in Table 1 consist of two optic gliomas and two malignant melanomas. No recurrence was pre-

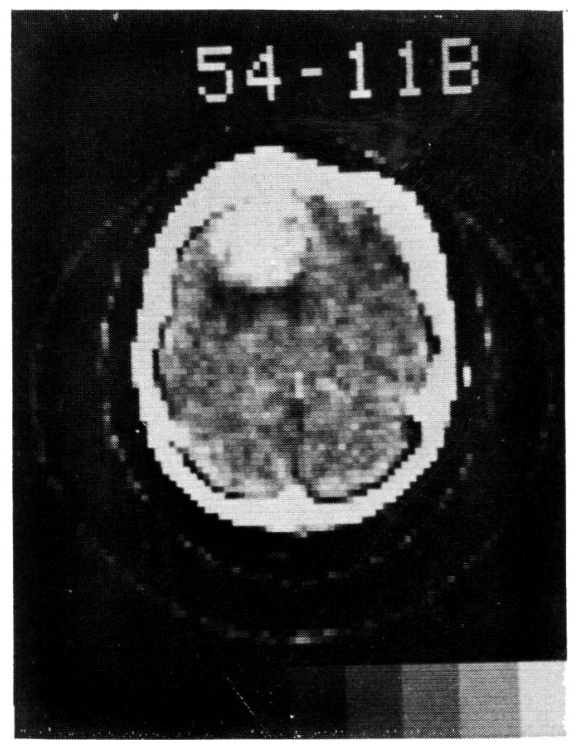

sent in the two optic gliomas but, in one of these, the orbit was almost completely obscured by metallic gauze and an equivocal opinion had to be given. Both the orbital melanomas showed recurrence; in one the recurrence was local in nature, the second showed a quite dramatic intracranial spread (Fig. $11,12)$.

\section{DISCUSSION}

It is apparent that optimal results are attainable in the evaluation of the post-operative tumor case only if certain guidelines are followed:

1. A baseline scan is done one month after surgery or radiation therapy.

2. The avoidance of metallic clips, gauze or plates (when possible) in cranial surgery.

3. The avoidance of use of positive contrast media intracranially prior to CTT scanning, also a pneumoencephalogram should not be done prior to CTT scanning for both create artefacts.
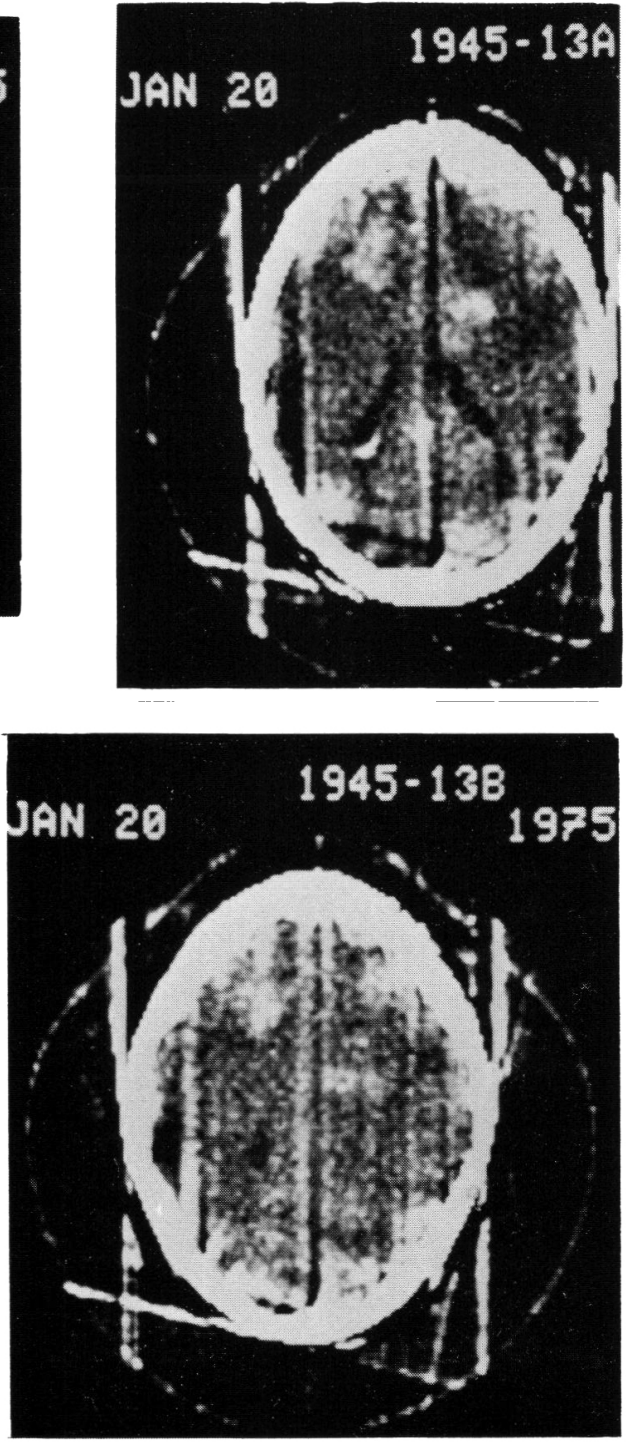

4. The liberal utilization of contrast enhancement in cases without a mass effect. In this series, $60 \%$ of cases had contrast enhancement.

CTT furnishes a positive diagnosis in a high percentage of cases in spite of the difficulties listed secondary to the previous surgery. In this particular group of cases, CTT is superior to pneumoencephalography, angiography or isotope scanning. Pneumoencephalography remains valuable in tumors of the perisellar region and in the low posterior fossa lesion. Angiography will 

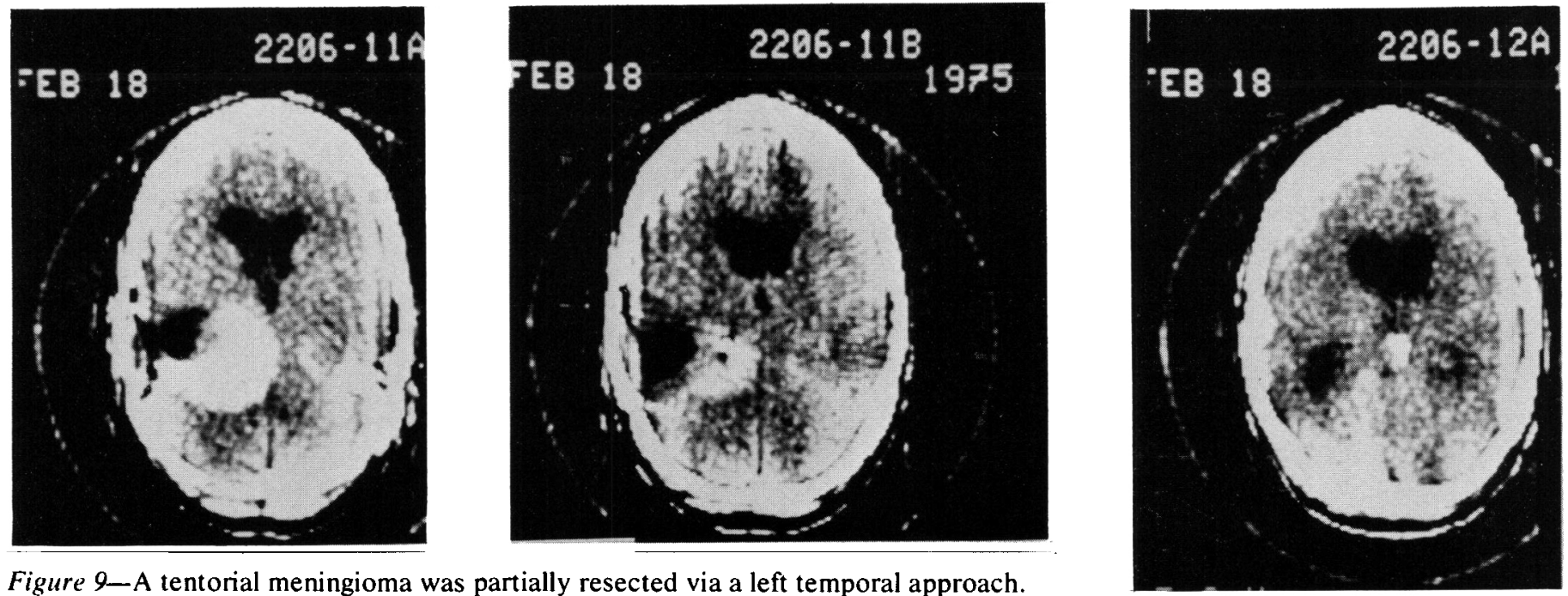

Figure 9-A tentorial meningioma was partially resected via a left temporal approach. The routine CT scan showed an area of decreased density adjacent to the bone flap due to gliosis of brain. Any remaining tumor and the fourth ventricle were not visualized. The infratentorial portion of the meningioma is hi-lited following contrast enhancement (level 11 A and 11B) with obstructive hydrocephalus shown at higher levels.
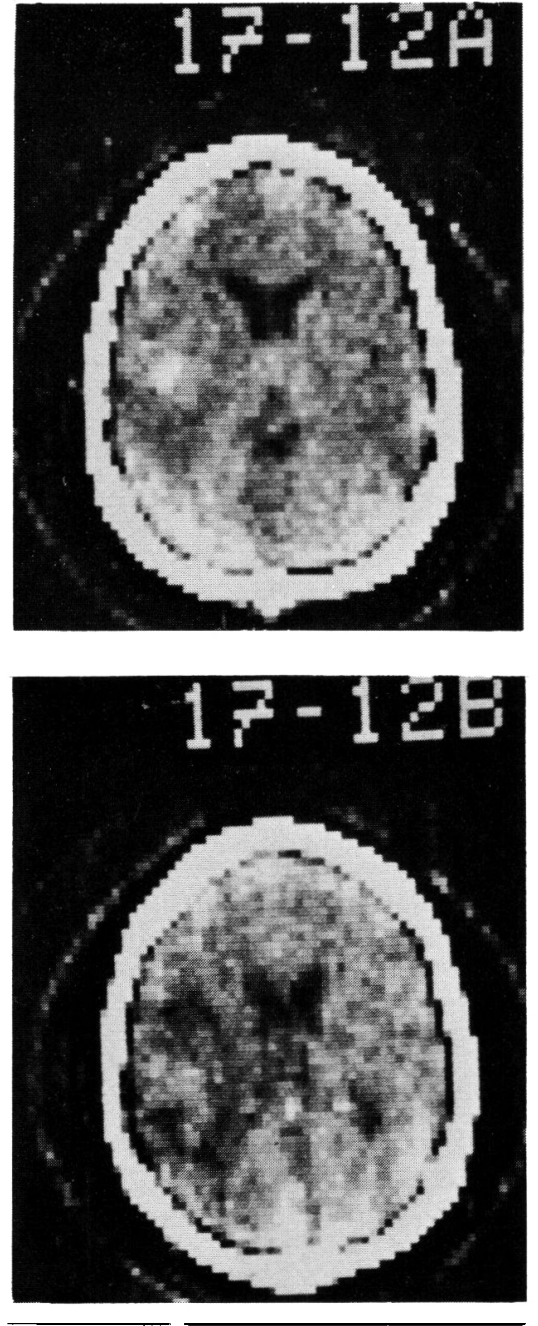

serve only a minor role, for tumor displacement and tumor vascularity was shown equally well with a CTT scan. The radio-nucleide scan may be falsely positive due to the bone flap even years after the surgery and also does not allow the detection of cerebral atrophy, of porencephaly or hydrocephalus.

In addition, it must be remembered that CTT scanning is a procedure without morbidity or complica-

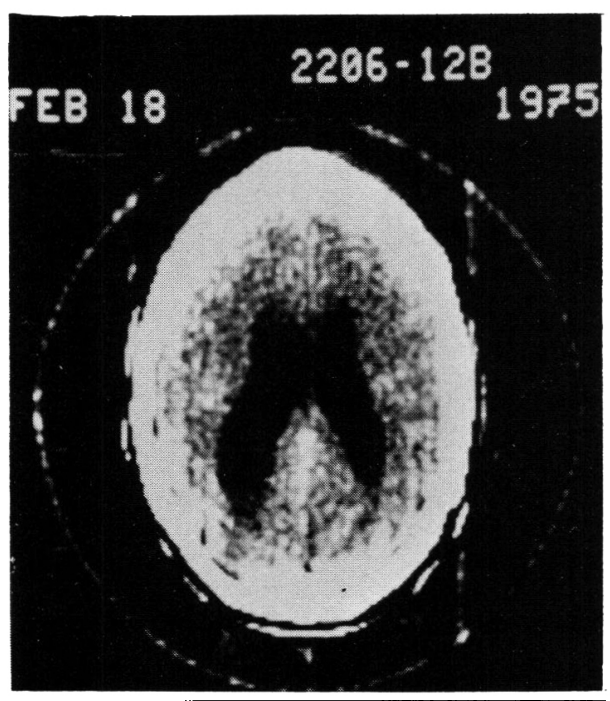

Figure 10-A left parietal melanoma was resected in August, 1973. CTT scanning in April 1974 showed recurrence with a large tumor mass in the left parietal area (levels $13 \mathrm{~A}$ and $\mathrm{B}$ ) and a smaller separate area of increased density lying antero-inferiorly (level 12A). Surgical resection was successful with a third resection in August 1974 following CTT visualization of further recurrence, some post-operative gliosis and left ventricular dilatation.
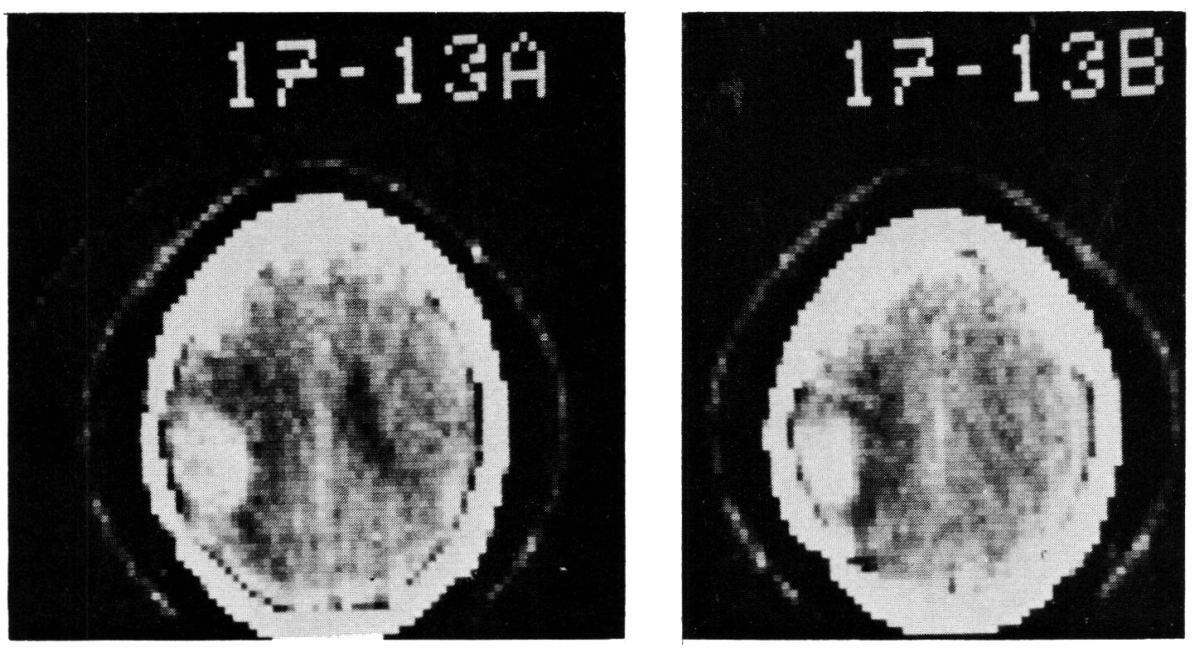
tion other than the low incidence attendant on the use of contrast media. CTT scanning offers a high degree of diagnostic accuracy. Its results in the assessment of early and late post-operative tumor cases are such that it is now the prime neurogradiological investigate procedure.

Grateful acknowledgement is made to the radiographic staff, the support of Winthrop Laboratories, Aurora, Ontario and the secretarial assistance of Miss A. Bartholomew.
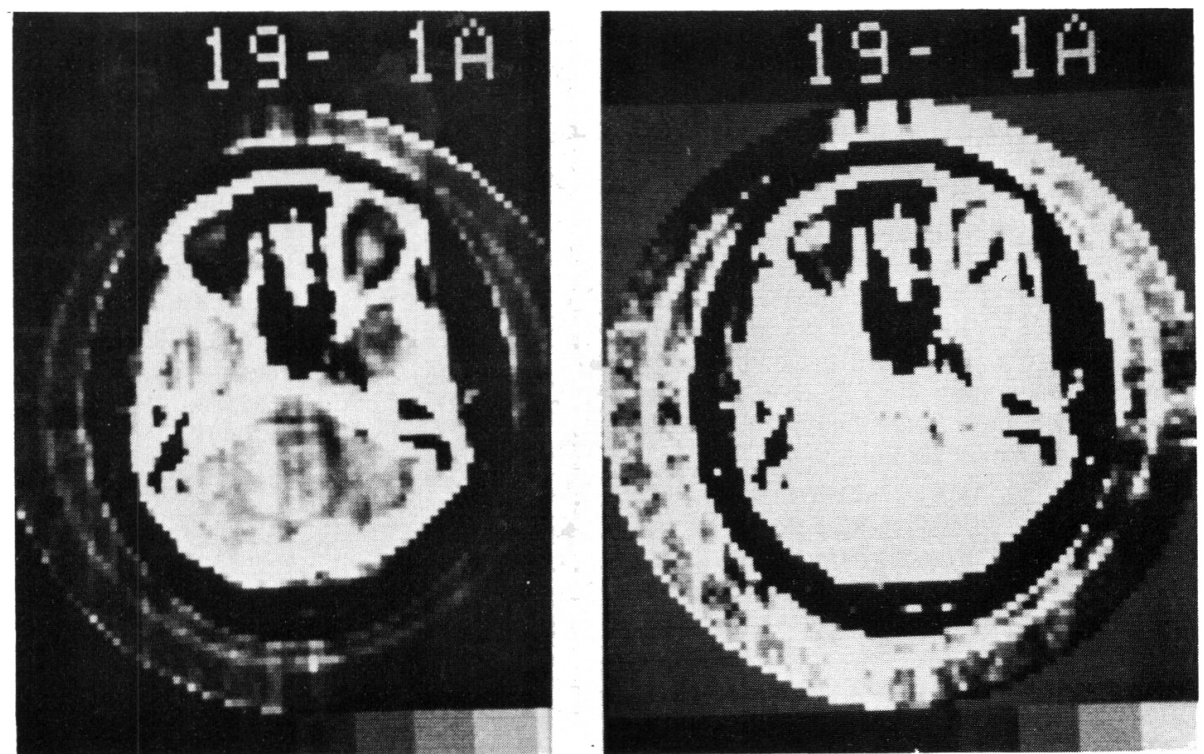

Figure $11-$ An area of increased density is demonstrated related to the right optic nerve with this shown to better advantage on the left by changing the measure of tissue densities via the controls of the cathode ray tube monitor. The eye was enucleated and pathology reported the tumor as a blue nevus of Ota, a variant of malignant melanoma (see Fig. 12).
Figure 12-A repeat CTT scan seven months later. Areas of increased density following contrast enhancement show the intracranial spread of tumor. At level 12B the tumor is just above the planum sphenoidale and extending to the right. At level 13B, there is a lobulated tumor mass visualized with further upward extension in level 14A. No intracranial extension was present on the initial study.
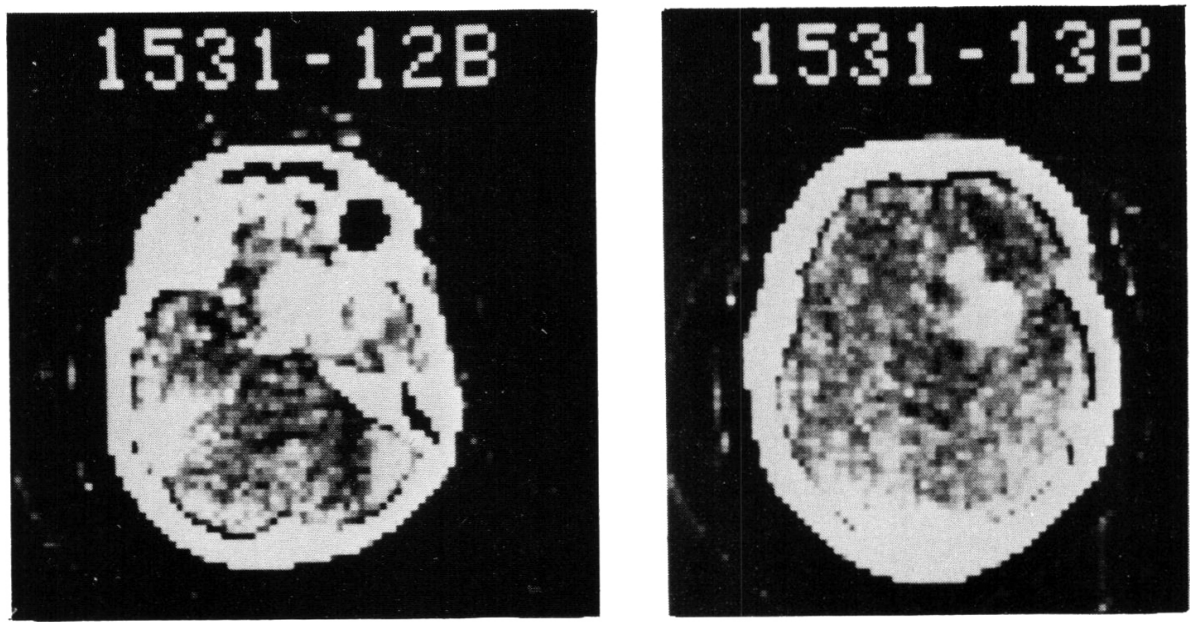
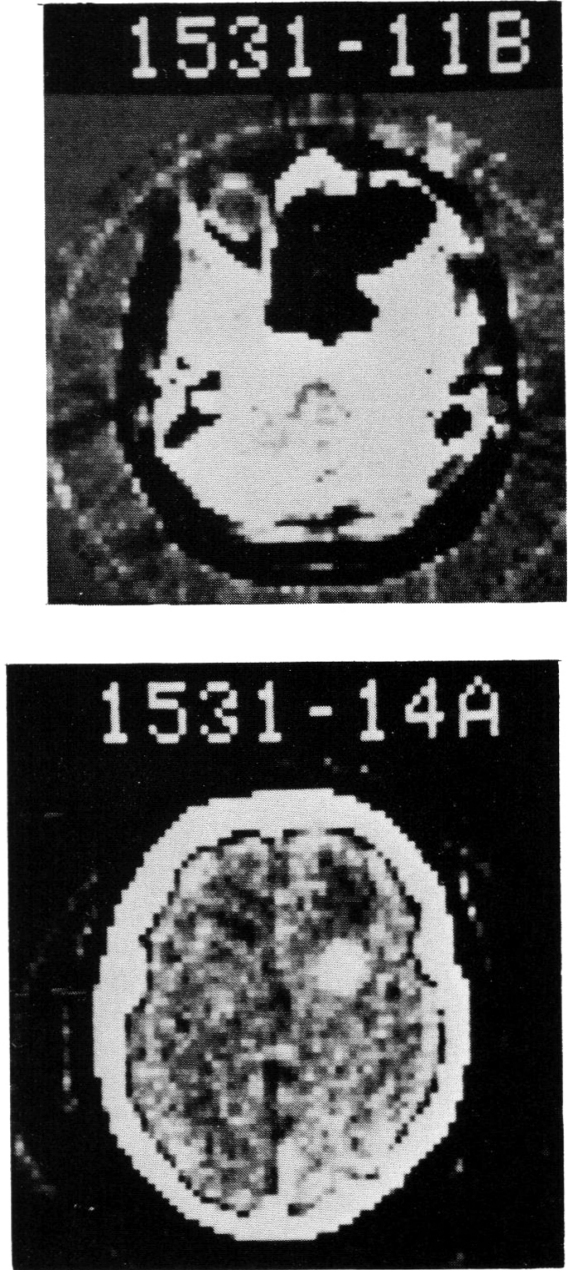


\section{REFERENCES}

AMBROSE, J. A. E. (1973). Computerized Transverse Axial Scanining (Tomography) Part 2: Clinical Application, British Journal of Radiology, 46, 1023-1047.

AMBROSE, J. A. E. (1974). Computerized $X$-ray Scanning of the Brain, Journal of Neurosurgery, 40, 679-695.

AMBROSE, J. A. E., LLOYD, G. A. S. and WRIGHT, J. E. (1974). A preliminary Evaluation of Fine Matrix Computerized Axial Tomography (EMI Scan) in the Diagnosis of Orbital Space-Occupying Lesions. British Journal of Radiology, 47, 747-751.

BAKER, H. L., JR, CAMPBELL, J. K., HOUSER, D. W., REESE, D. F., SHEEDY, P. F and MAN, C. B. (1974). Computer Assi.... Tomography of the Head. Mayo Clinic Proceedings, 49 , 17-27.

DAVIS, D. O. and PRESSMAN, B. D. (1974). Computerized Tomography of the Brain. Radiological Clinics of North America, 7 , 297-313.

DICHIRO, G., AXELBAUM, S. P., SCHELLINGER, D., TWIGG, H. L. and
LEDLEY, R. S. (1975). Computerized Axial Tomography in Syringomyelia. New England Journal of Medicine, 292, 13-16.

GAWLER, J., DUBOULAY, G. H., BULL, J. W. D. and MARSHALL, J. (1974). Computer Assisted Tomography (EMI Scanner). Its Place in Investigation of Suspected Intracranial Tumors. The Lancet, 2, 419-423.

HOUNSFIELD, G. N. (1973). Computerized Transverse Axial Scanning (Tomography): Part 1: Description of System. British Journal of Radiology, 46, 1016-1022.

LAMPERT, V. L., ZELCH, J. V. and COHEN, D. N. (1974). Computed Tomography of the Orbits. Radiology, 113, 351-354.

LEDLEY, R. S., DICHIRO, G., LUESSENHOP, H. J. and TWIGG, H. L. (1974). Computerized Transaxial X-Ray Tomography of the Human Body. Science, 186, 207-212.

McCULLOUGH, E. C., BAKER, H. L. Jr., HOUSER, O. W. and REESE, D. F. (1974). An Evaluation of the Quantitative and Radiation Features of a Scanning $X$-Ray Transverse Axial Tomograph: The EMI Scanner Radiology, 111, 709-715.

NEW, P. F. J., SCOTT, W. R., SCHNUR, J. A., DAVID, K. R. and TAVERAS, J. M. (1974). Computerized Axial Tomography with the EMI Scanner, Radiology, 110, 109-123.

PAXTON, R. and AMBROSE, J. A. E. (1974). The EMI Scanner: A Brief Review of the First 650 Patients. British Journal of Radiology, 47, 530-565.

PERRY, B. J. and BRIDGES, C. (1973). Computerized Transverse Axial Scanning (Tomography) part 3 Radiation Dose Considerations. British Journal of Radiology, 46, 1048-1051.

PETERS, T. M., SMITH, P. R. and GIBSON, R. D. (1973). Computer Aided Transverse Body-Section Radiography. British Journal of Radiology, 46, 314-317.

SCOTT, W. R., NEW, P. F. J., DAVIS, K. R, and SCHNUR, J. A. (1974), Computerized Axial Tomography of Intracerebral and Intraventricular Hemorrhage. Radiology, 112, 73-80. 